\title{
Concepciones de la enseñanza: un estudio en torno a docentes experimentados sin formación pedagógica
}

Mirtha Ricobaldi *

\section{Resumen}

Este trabajo surge de la tesis de Maestría sobre Educación; tiene como objeto identificar concepciones acerca de la enseñanza de los docentes universitarios experimentados que trabajan en formación docente, en el Instituto de Profesores Artigas, y carecen de formación pedagógica. Busca indagar las concepciones de enseñanza de esa Institución y de la Universidad de la República, analizando cómo repercuten en su concepción pedagógica.

Se realizó una búsqueda de antecedentes explorándose el estado actual de la cuestión, en temas como concepciones de enseñanza, modelos y perfiles docentes, formación profesional, relación teoría práctica, concepciones didácticas y transmisión de contenidos; contextualizándolos en el escenario de la cultura y las relaciones de poder.

De estos análisis resulta que el docente universitario que se apasiona por su disciplina identificándose con eso que es su profesionalidad, que se preocupa por la educación y se impregna de la cultura institucional, constituiría el tipo ideal de modelo docente.

\begin{abstract}
This work comes from a Master's thesis on Education. The main objective is to identify beliefs about education held by experienced university-level professors who work in teacher education at Artigas Teachers' Institute (ATI) and who lack pedagogical formation. The work inquires into the conceptions of education held in ATI and in Universidad de la República, analyzing how they impact on pedagogical conceptions. Research was performed exploring the precedents and current state of the issue, including topics such as concepts about teaching, teachers' profiles and models, professional education, the relation between theory and practice, didactic conceptions and the transmission of contents, in the context of a cultural background and power relationships. From the analysis, it is concluded that the ideal model of teacher would be a university professor with a passion for her discipline (identified with her profession), who is concerned about education and who is able to absorb the institutional culture.
\end{abstract}

\section{Fundamentación}

Consideramos importante realizar un trabajo sobre las concepciones de la enseñanza de los docentes experimentados, a nivel exploratorio descriptivo en razón de que los trabajos leídos sobre la formación docente apuntan a temas que tienen que ver con las representaciones, con conocer la asignatura, con la formación profesional, pero no se han retenido lecturas sobre las concepciones de enseñanza de los universitarios que se desempeñan como docentes sin la formación pedagógica. 
Por otro lado, actualmente en los ámbitos públicos y privados universitarios o de nivel terciario se percibe una preocupación sobre el tema y se tiene como demanda la formación de sus docentes.

En la formación profesional de los docentes así como en los modelos tradicionales de enseñanza sustentados en la agenda clásica de la didáctica, fue que se conformaron y reafirmaron las concepciones educativas de estos docentes, que sin embargo, se fueron fragmentando en su confrontación con la práctica docente y con los aportes de la nueva agenda didáctica. Sin embargo, una serie de temas no se encontraban inscriptos en esa agenda clásica, como el referente al pensamiento de los profesores, a cuál es el sentido de la enseñanza o cuáles son las consecuencias morales del acto de enseñar.

El propósito de este trabajo estuvo orientado a construir categorías interpretativas referidas a las concepciones acerca de la enseñanza de los docentes experimentados que no han tenido formación pedagógica.

Denominamos docentes experimentados a los universitarios que trabajan en Formación Docente como profesores, sin tener formación pedagógica, es decir, sin tener formación formal que los acredite como tales.

El docente experto es el que ha demostrado pericia en la enseñanza, basada en estructuras de conocimiento que permitan conductas eficientes (Ropo, 1991) ${ }^{1}$.

Realizar una indagación sobre los problemas planteados a los profesores y profesoras en relación con la práctica docente, en cuanto a lo que piensan, específicamente en cuanto a sus concepciones de enseñanza, es abrir espacios de discusión sobre la realidad educativa y las acciones que llevamos adelante en nuestro contexto profesional. Consideramos que es un objeto de análisis significativo para quienes se preocupan y trabajan en el ámbito de la didáctica universitaria, ya que genera una serie de interrogantes sobre el tema.

La Educación de nivel universitario implica, en muchos casos, la reproducción de un modelo donde lo importante es transmitir el conocimiento adquirido. El lugar que asume la preparación para la práctica profesional educativa es casi inexistente.

En este trabajo se parte de la idea de que si bien es muy importante, no alcanza con saber la asignatura, con tener un mayor o menor carisma, para que los resultados sean los correctos. Se hace patente que no alcanza sólo con trasmitir los conocimientos de una u otra asignatura, ya sea que se enseñe Sociología, Matemática o Historia. Ante todo se debe ser un buen docente, e impartir una buena enseñanza, "Aquella que deja en el docente y en los alumnos un deseo de continuar enseñando y aprendiendo, a la vez que la incorporación y el dominio de nuevos conocimientos" (Souto, 1996,117) ${ }^{2}$.

Poner la atención sólo en la transmisión de los contenidos y en el intercambio de ideas sesga el concepto; se debe ampliar el campo de análisis, priorizando lo que tiene que ver con los procesos de socialización, en las prácticas sociales. No se aprende sólo en el currículo oficial, sino en el proceso de las interacciones sociales que generan un entramado muy fuerte en las representaciones, valores y estrategias que serán parte de lo que configuran las concepciones del docente.

\section{4 - Universidad ORT Uruguay}


Una buena enseñanza supone algo más que la reproducción del contenido, comporta un quehacer comprometido con los acontecimientos sociales. Enseñanza implica una actividad llevada a cabo por dos o más personas interactuando entre sí, en un contexto determinado. Si agregamos el adjetivo "buena" deberíamos complementar este enunciado genérico con formulaciones tanto epistemológicas como morales. En cuanto a lo epistemológico no nos presenta dificultad, ya que tiene que ver con una justificación racional de la enseñanza. Pero el concepto moral se relaciona con lo ideológico, y lo podemos definir: desde el punto de vista funcionalista, como el buen desempeño de los roles a partir de la inculcación de las normas y los valores vigentes, o desde la visión materialista, para la que lo moral estará determinado por la reproducción de las normas y valores impuestos por la ideología dominante. Por tanto, en ambos conceptos, la definición de la buena enseñanza implica la incorporación de la ética y los valores en las prácticas de la misma.

Para ser un buen docente es necesario, pues, adquirir nuevos conocimientos que provienen de campos disciplinarios propios del quehacer educativo, como la Pedagogía, la Psicología Cognitiva, la Didáctica. Y además -agregaríamos otro componente -el compromiso con el papel que desempeñamos.

Sin negar el rol que compete a la teoría y a la investigación, consideramos que los pensamientos de los docentes generan concepciones; en este caso, las que nos interesan son las que tienen sobre la enseñanza, pues son instrumentos de deliberación permanente e influyen en las acciones pedagógicas.

Son ellas las que los orientan en la resolución de problemas, en las decisiones sobre su práctica, en las comprensiones de sus contextos. Y por ende, son decisivas en la calidad de la enseñanza que imparten, ya que involucran los campos intelectuales y éticos como esquemas conceptuales orientadores. Históricamente el rol del docente va unido al concepto de la reproducción social y conlleva, como toda tarea de enseñante, un caudal de responsabilidades en cuanto al compromiso social y a lo que significa ser, en este caso, formador de formadores.

La educación implica la dignificación de los actores sociales involucrados en la misma. Los docentes no pueden ser vistos por el colectivo como meros ejecutores de decisiones tomadas por otros, o de modas; por el contrario, consideramos que las ideas y valores subyacentes se hacen realidad en la medida en que los docentes las sientan como suyas, las adapten y las transmitan. Este proceso enfrenta al docente a la toma de decisiones, a recurrir a sus conocimientos previos, a sus concepciones de vida, a sus compromisos; a reformularse su profesionalidad, en un desarrollo dialógico constante. La función del docente, en su tarea de enseñar, se halla inmersa en una tensión dialéctica entre la reproducción social y el cambio que se supone puede y debe lograr. Sus concepciones juegan un rol fundamental puesto que deben otorgar al conocimiento, como instrumento construido social e históricamente, un sentido que va más allá de una lectura lineal.

En el campo de la enseñanza no se debe transitar por el camino de la fantasía en el que el docente es, cual Pigmalión, un escultor que da forma a la piedra bruta, o moldea el barro, creando a partir de sí mismo, y en el que el logro se da cuando se obtiene una forma de acuerdo a lo imaginado; cuando, como un Dios, crea un ser a su semejanza. Tampoco se debe ir hacia el otro extremo pensando que los hombres se forman por sus propios medios y que, cual Ave Fénix se consumen y renacen de sus propias cenizas (Ferry, 1991). Es lograr la realización de las personas, generando individuos críticos, analíticos, reflexivos. Desde el punto de vista social la educación implica reproducción; pero no es lo mismo reproducir la sociedad a través de modelos tradicionales para mantener el statu quo, que otorgarle el cometido de reproducir las desigualdades sociales, lo que implícitamente lleva a tomar opciones. 
Sin caer en un optimismo ingenuo, suponiendo que la enseñanza puede compensar las diferencias provocadas por una sociedad de libre mercado, con una fuerte diferenciación social, que conlleva posibilidades económicas, políticas y sociales, bien diferenciadas, pensamos que una enseñanza responsable encuadrada en un modelo didáctico, flexible y plural, es un reto para los profesionales en la educación que está directamente relacionado con la concepción de enseñanza que cada uno posee. Esto justifica la necesidad del conocimiento de las concepciones de enseñanza, ya que permiten interpretar las prácticas docentes con la intención de promover la reflexión sobre las mismas y lograr así la generación de buenas enseñanzas. "Las prácticas de la enseñanza presuponen una identificación ideológica que hace que los docentes estructuren ese campo de una manera particular y realicen un recorte disciplinario personal, fruto de sus historias, perspectivas y también limitaciones. Los y las docentes llevan a cabo las prácticas en contextos que las significan y en donde se visualizan planificaciones, rutinas, y actividades que dan cuenta de ese entramado" (Litwin, 1992, 94).

\section{El profesional universitario en su desempeño como docente}

En consonancia con lo expresado anteriormente, las prácticas docentes se configuran en el marco social que determina las concepciones de los docentes, las que influyen sustancialmente en su conducta y en su toma de decisiones, constituyendo una parte fundamental del contexto de la enseñanza. Hemos considerado un aporte importante para nuestra tesis la exploración sobre investigaciones y trabajos referidos al campo de la docencia universitaria ya que es allí donde realizamos nuestro estudio, encontrándonos con aportes con respecto al planteo de nuestro propósito, pero muy escasos en cuanto a las concepciones de enseñanza de los universitarios que se desempeñan como docentes.

Se asume que en la Universidad y en los niveles terciarios no se presentan problemas didácticos, relacionados con la formación de sus docentes; lo implícito es que allí se discute sólo lo importante que es lo científico. En la formación en los niveles terciarios y universitarios, se ha considerado secundario el aporte de conocimientos en el campo de la didáctica; se considera que la didáctica no tiene status social o cultural (Brousseau, 2001) ${ }^{3}$; el modelo aceptado ha sido el tradicional de la reproducción de los contenidos. El campo de la didáctica es considerado como un conocimiento devaluado, siendo aun para muchos un campo desconocido, impregnado de una serie de reduccionismos.

Referirnos a la docencia universitaria, es ver al docente inserto en la Institución que lo formó y con relación a las competencias que debe asumir con respecto a la Sociedad. La Universidad tiene como cometido formar profesionales comprometidos con el acervo social, así como concretar tareas en lo que hace a la gestión, investigación y producción, y son los docentes universitarios los portadores de esos cometidos. Hablar de la formación docente, como un insumo importante en la generación de las concepciones docentes con respecto a la enseñanza en los universitarios es interesante en razón de ser un campo que aún no está del todo acordado. Así, cuando se refiere al desarrollo profesional de los profesores, para algunos esta formación debe estar en manos de expertos, con conceptualizaciones desde arriba e incluso desde fuera, mientras que por otro lado se sostienen visiones más acordes con el pensamiento desarrollado en este marco teórico. Hargreaves (1992, 190).

Históricamente el docente universitario, "catedrático", afianzado en la tradición académica del conocimiento gozó de un reconocimiento y prestigio que surge por el hecho de su desempeño en la propia Universidad. En el imaginario social la Universidad es el lugar de producción intelectual y científica, logrando un gran respeto y reconocimiento social, que se hacía extensivo a su cuerpo docente. Las variaciones producidas en lo social, político y económico a nivel macro en el país han repercutido en la organización interna y en la percepción social de dicha 
institución. Factores que no son privativos de la Universidad, como menguados presupuestos, cercenaron muchas posibilidades, entre ellas, las de actualización, investigación y extensión. El catedrático dejó de ser el profesional, intelectual de renombre y reconocimiento social que dedicaba parte de sus horas a cultivar ese espacio que le era tan caro a nivel personal y en el imaginario social. Perdido ese espacio como profesional, se pierde la referencia académica y se sale en búsqueda de otros lugares donde promoverse; y allí procura reproducir su modelo. Pero esto no fue suficiente, ya que lo que acontece en la Universidad no es lo mismo que sucede en otros ámbitos educativos.

Para situar las concepciones que sobre enseñanza tienen los docentes universitarios que carecen de formación pedagógica y trabajan en la formación de formadores, siendo éstas un constructo social, encuadrado en los diferentes procesos sociales e históricos, debemos contextualizarlas en el escenario de las relaciones de poder y de cultura, según se expresa en el siguiente cuadro:

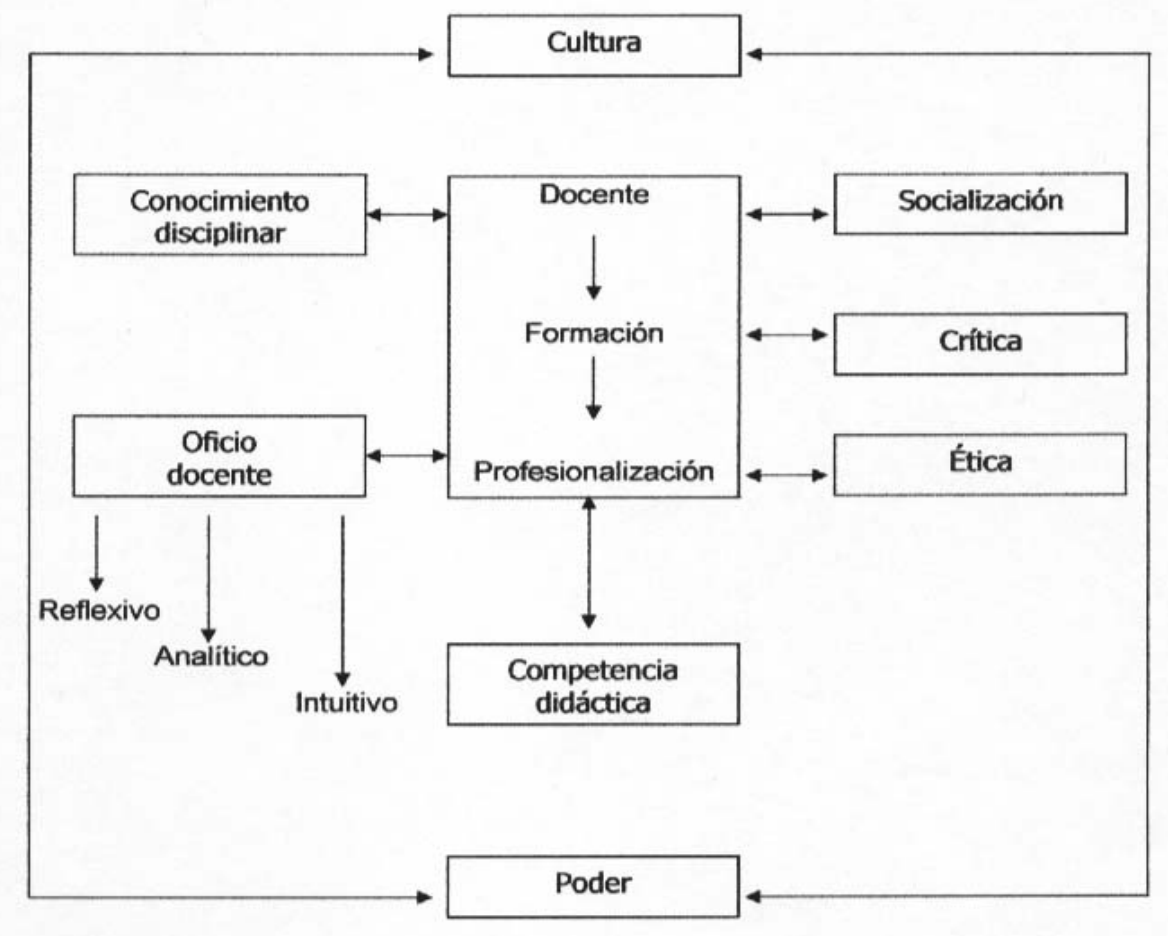

\section{Contextualización de las concepciones de Enseñanza}

Los docentes universitarios que han impregnado sus prácticas desde las visiones tradicionales, visualizan que esas concepciones totalizadoras del mundo construidas en la modernidad están en crisis. Surgen nuevas condiciones sociales, económicas y políticas que hacen tambalear y modifican el sistema de valores sociales que repercuten en lo social. En las prácticas de la enseñanza aparecen nuevos estilos que pretenden romper con los rituales, con la rutina de las "malas" clases magistrales, docentes que procuran emanciparse de las viejas ataduras, y del uso de metodologías arcaicas que encapsulan el conocimiento. La investigación didáctica hoy asume la necesidad de ampliar su desarrollo epistemológico reafirmando la idea de que ella debe ser considerada "teorías de enseñanza", ofreciendo instancias de reflexión para que los profesores o docentes cuestionen sus viejas metodologías fuertemente legitimadas que ya no resultan a la hora de favorecer procesos comprensivos para aquellos a quienes intentamos enseñarles algo. 
El docente universitario es un foco de atención fundamental en nuestro objeto de estudio, ya que desempeña un papel de primer orden en las prácticas de enseñanza. Presenta ciertos rasgos identificatorios en su profesión; se articulan en su práctica momentos teóricos y prácticos como parte de procesos dialécticos en la construcción del conocimiento. Como posición epistemológica presenta sus derivaciones en lo didáctico, se alternan espacios dedicados al tratamiento teórico de los temas con otros donde el análisis de la realidad y la práctica generan reflexiones, indagaciones e incluso construcciones teóricas.

Si bien a los docentes universitarios o de nivel terciario se les atribuyen las mismas características de cualquier profesor, en la Universidad aparecerán algunas específicas. En todos los ámbitos corresponde transmitir la cultura imperante, socializar, procurar un amplio desarrollo personal de los individuos. Pero mientras en los niveles primarios y secundarios el rol es prioritariamente formativo, en los universitarios y terciarios, aunque se mantienen los criterios formativos, lo prioritario es conformar individuos críticos, reflexivos, analíticos, que se apropien del conocimiento y lo recreen. La responsabilidad de estos docentes sería dar una respuesta adecuada a las circunstancias cambiantes de los entornos económicos, laborales y culturales, implementando una formación flexible que responda a las nuevas demandas que se van produciendo. Es una construcción multirreferencial compleja; no es un modelo acabado, sino un modelo a construir desde la práctica y en una permanente relación comprometida consigo mismo y con su entorno. Las universidades deben aparecer como unidades responsables de la producción y distribución del conocimiento, así como de la formación de sus docentes.

\section{Fundamentos metodológicos}

La formulación teórica y metodológica de este trabajo se centró en una perspectiva fenomenológica, que si bien está engarzada en una amplia gama de marcos conceptuales y escuelas de pensamiento, se acotó en el interaccionismo simbólico y la etnometodología desde una perspectiva crítica y por los aportes de lo que se definió como la nueva agenda didáctica. Desde el interaccionismo simbólico entendemos que son los significados sociales que los actores asignan los que determinan sus acciones en los procesos de interacción de la vida cotidiana. Desde la incertidumbre generada por la mirada del comienzo de un nuevo milenio, las Universidades deben aparecer como unidades responsables de la producción y distribución del conocimiento, así como de la formación de sus docentes. Este camino implica entender de una manera clara y comprometida la actividad de enseñar (Candau, 1989).

El enfoque interpretativo nos permite describir los procesos de la interacción educativa, con la finalidad de brindarnos elementos para la construcción social de los sentidos de lo acontecido. En cada situación se construyen sentidos y es importante, para este modelo de indagación, aportar elementos que nos permitan describir las interpretaciones que los sujetos realizan de aquello en lo que son actores: la interacción didáctica.

Si bien los diferentes actores constituyen comunidades, por afinidades, profesiones, tareas a cumplir, son los individuos sin embargo, como integrantes de esas comunidades, como parte de las instituciones en las que trabajan, quienes llevan adelante las acciones sociales con sentido e intencionalidad referenciadas en la interpretación de la acción del otro o de los otros. Cada uno dirá y hará cosas diferentes porque lo interpretará desde su capital social, desde su experiencia, en un proceso de construcción dinámica permanente. Serán por tanto las interpretaciones las que definirán las situaciones. 
Desde lo teórico y epistemológico, la perspectiva etnometodológica permitirá que sean los actores sociales los que le otorguen sentido a la realidad, revalorizando la vida cotidiana, lo que nos permite comprender, permitiendo la interpretación. El docente no se puede abstraer de la institución en la que se desempeña; esta lo construye, lo contiene. Es una institución vívida, dinámica, en permanente elaboración, que le exige un compromiso ético, social, responsable; en la que detrás del esquema de poder legitimado, está la construcción de la moral. No es la imagen de la institución tradicional en la que las funciones primordiales son socializar de acuerdo con los patrones normativos vigentes y por tanto transmitir los conocimientos, pautas y valores acordes a tal fin. Por tanto sus concepciones repercutirán en el estilo del trabajo docente, en la selección de los contenidos y la apropiación de los saberes, en la intencionalidad que le dé a sus mensajes.

\section{Diseño metodológico}

La metodología utilizada en este trabajo está enmarcada en un modelo mixto con un enfoque cualitativo, de corte fenomenológico que se orienta a la construcción de categorías interpretativas, con sustento en la etnometodología. Esta investigación se efectuó en un nivel de diseño exploratorio-descriptivo, en un contexto de descubrimiento localizado de focalización progresiva que nos permite llegar a un nivel descriptivo enmarcado en las corrientes interpretativas, ya que nuestro objetivo es interpretar más que descubrir.

La investigación se realizó durante el año 2003, en Montevideo, en el Instituto de Profesores Artigas y en la Universidad de la República. Del primero se seleccionaron los universitarios que no tienen formación docente y trabajan como profesores y el equipo de Dirección. Se realizó también un análisis documental dirigido a detectar su perfil institucional y las concepciones de enseñanza implícitas en sus normas fundacionales. En la Universidad de la República se trabajó con los documentos existentes en ese ámbito para poder deducir, de su estudio, las concepciones de enseñanza imperantes en dicha institución.

\section{Técnicas utilizadas para la obtención de los datos}

La colecta de datos para este trabajo se efectuó mediante diferentes instrumentos, herramientas o técnicas:

- En primer lugar llevamos a cabo un relevamiento de datos entre todos los docentes del IPA para determinar cuáles eran los universitarios que se desempeñaban como docentes sin tener formación pedagógica. Dentro de este grupo trabajamos con una muestra intencional, determinada por aquellos que fueran efectivos o tuvieran tres años de antigüedad en el desempeño del cargo y con un puntaje en Informe de Dirección o Inspección no menor a los 81 puntos, que equivale a la calificación Muy Bueno. La cantidad de docentes que se encontraban en la situación indicada determinó nuestro Universo de Análisis.

- En segundo lugar se realizaron entrevistas semi-estructuradas y en profundidad, de corte fenomenológico, a los docentes seleccionados como modelos de indagación.

- En tercer lugar se realizaron entrevistas semi-estructuradas al Equipo de Dirección del IPA para la obtención de información significativa.

- En cuarto lugar se procedió a un Análisis documental, de contenido, de los documentos y textos obtenidos en el IPA y en la Universidad de la República, lo que nos permitió detectar las concepciones implícitas o explícitas sobre Educación y Pedagogía vigentes en ambos centros.

- En quinto lugar se logró un acercamiento a la dimensión contextual de ambos centros de enseñanza, a través de un análisis de los documentos que contienen la historia, los mandatos y los cometidos institucionales. 
- Por último se realizó una triangulación a los efectos de la validación, entre los datos surgidos del análisis documental y de las entrevistas realizadas a los docentes seleccionados y al equipo de Dirección de IPA en su calidad de informantes calificados.

Se trabajó con entrevistas semi-estructuradas de corte fenomenológico puesto que los datos obtenidos, en tanto fuente de significado, nos permiten describir e interpretar la realidad. Estas entrevistas se estructuraron basándose en tres niveles diferentes de análisis: el primero exploró el recorrido docente del entrevistado, la reconstrucción de su historia laboral, su formación y antigüedad en el desempeño del rol docente. El segundo pretendió incursionar en el campo de la planificación y evaluación, mediante la detección de sus estrategias de intervención, sus tiempos, sus espacios innovadores. El tercero, entrelazando los resultados obtenidos en los dos anteriores, permitió reconstruir las claves de porqué se enseña.

Este instrumento nos permitió entonces profundizar y comprender mejor las concepciones de los diferentes actores sociales. Estos son los que le otorgan sentido a la realidad, revalorizando la vida cotidiana y permitiéndonos, a través de sus acciones y de sus expresiones, interpretarla. Así, la información surge de la narrativa del propio docente más que de la pregunta explicita del entrevistador.

Cabe señalar, finalmente, que las entrevistas en profundidad, de larga extensión en su mayoría, así como la observación de los entrevistados, se constituyen en género narrativo, casi biográfico en algunos casos. Son utilizadas en esta investigación empírica junto a las realizadas a los informantes calificados y a los análisis documentales, no para reconstruir la biografía de los entrevistados, sino para detectar su concepción de enseñanza.

El análisis documental se realizó mediante el análisis de texto, ahondando en aquellos aspectos que, sumados a los datos obtenidos anteriormente, nos permitieron generar las categorías interpretativas que favorecen la comprensión e interpretación de nuestro objeto de estudio. Mediante esta técnica se abarcaron dos aspectos, uno en cuanto a concepciones de enseñanza y otro en lo referente a lo contextual e institucional, teniendo en cuenta que consideramos al IPA como la institución emblemática en Formación Docente, no solo por su localización en Montevideo, sino por ser un referente insoslayable a nivel nacional.

Como forma de validación metodológica se realizó una triangulación. Con ella se exploró la convergencia de las percepciones y de los enfoques de análisis, examinando las diferencias entre las expresiones y/o descripciones obtenidas desde cada fuente de información. La ventaja de esta técnica es que nos permitió alcanzar más dimensiones de la realidad social; abarcar una información más compleja y diversificada; posibilitándonos reforzar, cuestionar o cambiar algunos de nuestros supuestos teóricos.

\section{I nstituto de Profesores Artigas}

En la dimensión contextual, el Instituto de Profesores Artigas tuvo su creación por el Art. 49 de la Ley 11.285 en sustitución de la Sección Agregaturas que funcionaba en Enseñanza Secundaria e inició sus actividades docentes a principios de 1951. Situado en el barrio de la Aguada, su local con distribución espacial panóptica (Foucault, 1991) típica de las instituciones educativas, es un elemento fundamental que coadyuva a crear un clima específico que determina asimismo parte de la propia construcción docente y de la historia de vida de todos aquellos que constituyen la médula viva de la institución. El análisis de contenido de sus documentos nos permite recrear su historia desde otra mirada, buscando en los diferentes textos analizados los mandatos fundacionales que informan las concepciones de enseñanza de la Institución. 
Los datos que consideramos relevantes para nuestro estudio surgieron entonces del análisis de:

- La Ley No 11.285 del 2 de Julio de 1949, de creación del Instituto de Profesores Artigas.

- Los Anales del IPA, que son las primeras publicaciones en las que aparecen artículos de diferentes actores que hacen referencia al surgimiento y descripción de la Institución, las dificultades surgidas en las distintas etapas de su desarrollo.

- El Estatuto del Funcionario Docente de la Administración Nacional de Enseñanza Pública (ANEP).

- La ley de Enseñanza No 15.739, del 28 de marzo de 1985.

Las actividades del IPA se conformaron a través de un Plan de Estudios de 4 años de duración que posibilitaría la formación de docentes para la enseñanza media en las distintas especialidades que integraban el nivel medio, atendiendo fundamentalmente tres aspectos esenciales: la formación disciplinar, la formación pedagógica y la práctica docente. Se hace particular hincapié en la especialización de la asignatura otorgándosele un 50 \% de los cursos.

En el año 1977 - inmersos en pleno período de la Dictadura en el Uruguay - y a través de la Ordenanza No 30 se produce una reforma por la cual el IPA pasa a integrar el INADO (Instituto Nacional de Docencia General Artigas). Con esta reforma se reduce el plan de formación inicial de 4 a 3 años, perdiendo competencias en cuanto a perfeccionamiento docente, formación de profesores de Ciencias de la Educación y formación de profesores agregados a las distintas especialidades.

Durante el año 1986, en la etapa de restauración democrática, se vuelve al formato fundacional de 4 años de formación inicial, y se incorporan algunas carreras cortas como proceso innovador y con carácter de especialidad.

Actualmente sigue vigente este Plan 86 que lleva 18 años de ejecución en la práctica, con un porcentaje amplio de docentes que lo han enriquecido y fortalecido con su experiencia y formación, realizadas en 21 especialidades de profesorado -cinco de ellas en modalidad de carrera corta- que cuentan con un currículo de asignaturas generales correspondientes a las Ciencias de la Educación, de base general y formativa para todas las especialidades, que se distribuyen espacial y temporalmente a lo largo de los 4 años de duración de la carrera, y en asignaturas específicas por especialidades.

Esta formación se complementa con la unidad didáctica-práctica docente, que se concreta en el contexto de enseñanza media, directamente vinculada a la didáctica específica de la Especialidad.

\section{Universidad de la República}

Los inicios de la Universidad nacional se remontan a la primera legislatura de nuestro Estado (1830 a 1834) cuando, por iniciativa del Presbítero Dámaso Antonio Larrañaga, se sancionó su Ley de creación el 8 de Junio de 1833.

En 1836 se organizan las primeras cinco cátedras pasando a denominársele Casa de Estudios Generales. En 1838, el Presidente Oribe le asignó a esta Casa el carácter de Universidad Mayor de la República. La Guerra Civil que mantuvo en conflicto al país hasta 1851, frustró, en los hechos, esta primera etapa fundacional. Terminado el conflicto y por decreto del 14 de Julio de 1849, el Presidente Joaquín Suárez ordenó la inmediata instalación de la Universidad de la República, que fue inaugurada el 18 de Julio, teniendo como primera sede la Iglesia de San Ignacio. 
En ese mismo año el primer reglamento orgánico le otorgó la totalidad de la instrucción: primaria, secundaria y superior.

En 1877 el Presidente Latorre emite el Decreto-ley de Educación Común, recogiendo las ideas del proyecto educativo de José Pedro Varela, lo que significó la consagración de los principios de gratuidad y de obligatoriedad de la enseñanza, al tiempo que profesionalizó el magisterio determinando la separación de la enseñanza primaria, que quedó así independizada de la Universidad.

Actualmente ocupa un local construido especialmente en 1906 para albergarla, en el corazón del barrio de El Cordón. Su edificio, encuadrado en tendencias del renacimiento clásico, con un estilo de monumentalidad de carácter serio y formal como correspondía a la época, fue inaugurado en 1911 por el Presidente Williman.

La Universidad fue organizada por la Ley Orgánica de 1908 que atribuyó potestades al Poder Ejecutivo para designar directamente al Rector y para aprobar los programas de estudio. En 1917 la nueva Constitución consagró la autonomía de la enseñanza pública, que pasaría a ser administrada por un Consejo autónomo. En 1935 se elabora un nuevo Estatuto de la Universidad que recoge los postulados reformistas debatidos a partir de los encuentros de Córdoba de 1918, transformando los fines de la Universidad, reafirmando su autonomía y proponiendo un sistema de cogobierno entre docentes, estudiantes y egresados. En este mismo año se segrega la Enseñanza Media del ámbito universitario, estableciéndose un nuevo ente autónomo para su conducción. Luego de diversas reformas constitucionales que mantuvieron el principio de autonomía universitaria creado en 1917, en la reforma del 52 se prevé la elaboración de una nueva ley orgánica que estuvo pronta en 1958. El nuevo texto legal desarrolló los principios y soluciones que habían ido tomando cuerpo en la evolución histórica: autonomía universitaria, gobierno de co-participación de los tres órdenes, principio de libertad de cátedra y de opinión, definición precisa de los fines de la Universidad. La crisis económica y social de los 60, potenciada por el Mayo del 68 francés, generó una especial preocupación sobre el papel de la Universidad y llevó al Rector Maggiolo a impulsar un plan transformador que no pudo ponerse en práctica debido a la intensificación de los conflictos sociales, políticos y culturales que desembocaron en la grave crisis nacional que condujo a la caída de las instituciones democráticas con el golpe de estado del 27 de Junio de 1973.

La Universidad se moviliza entonces tratando de demostrar que aún puede adoptar posturas creativas, distintas y responsables y, a través de su Comisión para el estudio de los Problemas Nacionales (PRONA), organiza lo que sería el último ciclo de su etapa autonómica, bajo el título de "El Uruguay y su Universidad en 1973. Hacia la construcción de un destino nacional".

La radical postura universitaria enfrentada al poder militar determinó la Intervención de la Universidad el 27 de Octubre de 1973 y la ocupación de todas sus dependencias por las Fuerzas Armadas. El Ministerio de Educación y Cultura se hizo cargo de la administración general de la Universidad arrestándose al Rector, a los Decanos y al Consejo Directivo Central.

Desde 1974, la Universidad intervenida se sumió en un proceso de desmantelamiento general, mientras se aislaba voluntariamente del entorno. No apareció ningún modelo alternativo de Universidad diseñado por el poder fáctico, sino que todo se limitó a la asignación de la exclusiva y tradicional función de formar profesionales. Casi desaparecieron los proyectos de investigación científica y los estudios sobre la problemática nacional, en tanto fueron clausurados numerosos servicios universitarios. 
También se procedió a una sistemática destrucción de la estructura académica, al suprimirse asignaturas y reformarse los planes y programas de estudio, dando paso a una conciente improvisación, que fue completada por la aplicación, desde 1975, de mecanismos restrictivos de la admisión de estudiantes que recién se modificó en 1982.

El proceso de transición de 1980 a 1984, culmina con la restauración democrática y el paulatino retorno a la normalidad. En ese lapso los universitarios concertaron con los grupos políticos y los gremios el retorno de la Universidad a la vida autónoma. En Agosto de 1984 cesa la intervención y en 1985 se reimplanta el co-gobierno de los tres órdenes reeligiéndose el Rector y Decanos destituidos en 1973. Electas poco después nuevas autoridades, éstas se abocaron inmediatamente a la tarea de apoyar a los polos más activos en investigación, docencia, capacitación y extensión, con lo cual se marca el inicio de una política de renovación científica y tecnológica, adecuando al mismo tiempo las carreras profesionales a las necesidades futuras del país. Desde el Rectorado se impulsa una política de apertura centrada en cuatro grandes ejes: la apertura institucional, social, regional e internacional.

En la década de los 90, se crea la Facultad de Humanidades y Ciencias de la Educación siendo en este entorno que vemos emerger una creciente preocupación por la formación docente en el nivel terciario al haberse estructurado, para todas las disciplinas que se dictan, dos terminalidades: docencia e investigación, que son precedidas por una formación previa común. La opción Docencia, que aparece por primera vez en el currículo universitario en forma orgánica, persigue la adquisición de una buena formación teórica y del necesario instrumental científicotécnico para conocer la realidad educativa.

En el 2000 las autoridades universitarias elaboraron, discutieron y aprobaron el Plan Estratégico de la Universidad, que fijó las metas para el accionar de esta institución durante el quinquenio 2000-2004. En este documento aparece explicitada una preocupación por la formación didáctica del personal docente. El Plan Estratégico articula diversos Proyectos Institucionales que tienen por objetivo atender algunas de las demandas específicas planteadas en cuanto a la Formación Didáctica de Docentes Universitarios y Profesionalización de la Carrera Docente.

Interesa destacar que, cuando se reseñan los antecedentes en esta materia se consigna que diferentes servicios universitarios crearon y desarrollaron departamentos de apoyo a la enseñanza desde 1962. Esta tendencia se generalizó a principios de la década de los 90 cuando se creó la Comisión Sectorial de Enseñanza (CSE) de la Universidad de la República.

\section{Cuando hablan los docentes...}

Todas las entrevistas fueron estructuradas tomando, como punto de partida de las narrativas personales, un disparador común que tendía a ubicar al entrevistado en los inicios de su formación profesional, para intentar reconstruir su historia laboral y el derrotero seguido por cada uno de ellos hasta llegar al desempeño de su tarea docente.

En el desarrollo de las historias se puede observar que tiende a establecerse una pauta casi general que marca un inicio ajeno a la formación docente, seguido por una etapa de tránsito por experiencias docentes, formales o no, que va acercando paulatinamente a cada entrevistado a los institutos de formación docente para allí procesar su acceso a la formación de docentes para la enseñanza media. 
Al comenzar el trabajo de análisis de las narraciones recogidas apreciamos que en todas ellas emerge un rasgo en común que surge desde los primeros planteos de los entrevistados cuando aseguran no tener formación docente pero ejercer el rol docente sin dicha profesionalización.

De los relatos surge así que para los entrevistados la formación docente no pasa por lo formal, sino que lo que les da la posibilidad de ser docentes, o lo que los transforma en docentes, es el haber ejercido en algún momento, no importa en qué condiciones, ni en qué lugar, ni en qué forma, el rol docente.

Todos los entrevistados son hombres y mujeres de diversas edades y extracción social, egresados universitarios, con más de tres años en docencia directa en Formación Docente, con informes de Dirección o de Inspección superiores a 81 puntos, lo que los categoriza para este trabajo como expertos. Trabajan en el IPA y están formados en diferentes momentos, en diferentes especialidades y como expertos en un campo de conocimiento específico y disciplinar.

Partiendo de la revisión de sus entrevistas se intenta trazar caminos, tender líneas que permitan llegar a dilucidar sus concepciones de enseñanza. Estas concepciones se construyen no sólo en espacios formales, curriculares y en una formación didáctico-pedagógica sino también en los mitos identificatorios sociales, en los constructos simbólico-culturales que conforman el sustrato de las narrativas.

En las voces de los diferentes protagonistas se busca entonces lo que está detrás de lo verbalizado; lo que, como trama sustenta los diferentes relatos. Se trata de desentrañar primariamente esos aspectos simbólicos de la vida social en sus significados individuales. Las palabras adquieren un poder simbólico, revelador, se pueden hacer cosas con palabras.

Pero también debemos prestar atención, en el trabajo de campo, a la descripción de los diferentes trayectos recorridos por los protagonistas en sus reconstrucciones sociales. De esta forma, la mirada transita por un contexto de descubrimiento y redescubrimiento que permite llegar a niveles descriptivos; el desafío fue armar la genealogía del concepto de enseñanza en clave foucaultiana mediante un trabajo arqueológico, paciente y cuidadoso, que se evidencia en el diseño de la investigación.

Nuestra propuesta es atender no sólo a lo expresado, a la conducta observada, sino hurgar en las concepciones que determinan esa conducta. Así, se construye a partir de ejes temáticos, de centros de interés y en razón de las expresiones recurrentes encontradas en las entrevistas, sin dejar de captar la heterogeneidad. Las voces de los docentes narran, describiendo acontecimientos, procesos individuales en contextos sociales y culturales. Las palabras toman sentido, y en el propio transcurrir del discurso los protagonistas van descubriendo nuevas y renovadas interpretaciones de sus propias historias de vida que se entrelazan con el armado de su rol docente, conformando así, a través de recuerdos, expresiones, representaciones, aspiraciones e idealizaciones, un primer plano de claro contenido concreto, muy cercano a la empiria.

Las palabras se vuelven imagen y las imágenes se plasman en contenido que se adjetivan a partir de la subjetividad del actor. Es este plano que permite, a través de un proceso de abstracción, la configuración de un segundo plano de enunciados categoriales más alejados de la realidad, lo que nos permite realizar una construcción teórica desde el campo. 


\section{Las voces de los otros}

Continuando con las voces de los diferentes actores involucrados en este trabajo llegamos a los relatos del equipo de Dirección del IPA. Si bien nuestro objeto de estudio está centrado en aquellos docentes que ejercen la función sin la formación pedagógica, hemos considerado importante escuchar lo que denominamos las voces de los otros. Aquellos que conocen la Institución desde otra mirada, la institucional.

A través de sus relatos la Institución se personaliza, adquiriendo un protagonismo que marca la historia personal de los integrantes del equipo de Dirección. Se convierte en parte de ellos mismos ya que la han vivido desde diferentes perspectivas que han generado un fuerte involucramiento y cambios en la óptica de análisis.

Consideramos que los entrevistados son informantes calificados ya que desempeñan el cargo de Dirección en el Instituto y a su vez son egresados de esta Institución, con diez y veinte años de experiencia en la docencia. Conocen al IPA como estudiantes y como docentes, y por tanto, la percepción institucional expresada es subjetiva, personalizada, lo que genera un fuerte sentimiento de pertenencia, el que se hace visible en sus expresiones donde sus historias personales y la historia de la Institución se entrelazan estrechamente.

Ambos Directores tienen perspectivas analíticas diferentes puesto que se han formado en disciplinas diferentes, la Historia y la Biología.

\section{Enunciando categorías}

Una vez analizados los contenidos de las entrevistas realizadas a los docentes y al equipo de Dirección del IPA y habiendo procedido al análisis documental de las dos Instituciones implicadas en este trabajo, podemos enunciar las siguientes formulaciones categoriales que informan las Concepciones de Enseñanza de los universitarios que trabajan en Formación Docente sin formación pedagógica:

1. La fuerza del imaginario social en relación a la profesión docente. Teniendo en cuenta que todos los entrevistados han llegado al IPA, por diversas razones -económicas, vocacionales, casuales- $y$ con diferentes experiencias anteriores de práctica docente, es evidente que ingresan a la Institución sin tener una concepción teórica formal de lo que implica ser un docente formador de formadores. Previo a este ingreso al IPA, es la fuerza del imaginario social implícito en sus historias personales (juegos infantiles, relaciones parentales) la que construye su concepción docente, que a partir de ese momento deberá ser confrontada con las construcciones teóricas que constituyen la finalidad primaria de la Institución.

2. El peso de lo disciplinar Como todos los entrevistados provienen de los ámbitos universitarios, el desarrollo de su labor docente dentro del IPA aparece fuertemente marcado por el rasgo dominante de la enseñanza universitaria, a saber: es buen docente aquel que sabe de lo que habla y ama profundamente su disciplina encarando su labor con un alto contenido ético. Esa impronta eclipsa los contenidos didáctico - pedagógicos que la Institución debe cumplir según mandatos fundacionales, generando un escaso interés por la formación docente formal y una marcada preferencia por todo aquello que implica una mejora de práctica docente. 
3. La construcción de los modelos docentes Dado que los entrevistados al ingresar al IPA no tienen definido formal y teóricamente un modelo docente, normalmente reproducen los que han construido a través de sus experiencias personales previas (entorno y antecedentes familiares, docente memorable). En la confrontación dialéctica teoría-práctica es que va surgiendo y se decanta la construcción del modelo docente que, en definitiva, es el que transmiten a sus educandos. El apoyo de los iguales y su reconocimiento son piezas fundamentales de esta construcción.

4. La impronta de la didáctica normativa Los modelos imperantes en el recorrido educativo de los entrevistados están fuertemente marcados por una didáctica prescriptiva, basada en modelos normativos tradicionales. Las concepciones vigentes en cada momento social e histórico condicionan fuertemente las prácticas de aula.

5. Las relaciones de poder que legitiman las prácticas de enseñanza En las narraciones de los entrevistados surge que consideran al poder como parte constitutiva y legitimante de la función docente. El poder puede ser expresado de formas diferentes, con la imposición de los modelos aceptados ya sea que ésta se realice a través del ejercicio de la autoridad, que se logra por vía del honor social, o mediante abuso y autoritarismo.

6. La Institución y el aula como marcos de referencia El acceso al IPA, institución percibida como de fuerte arraigo y alto valor simbólico en el imaginario docente, matriz de referentes que van desde los niveles académicos a los netamente emotivos de corte personal, se transforma en un logro y un desafío para aquellos que finalmente ingresan al mismo. Si la institución desafía, el aula fortalece, porque es en ella donde el docente encuentra el espacio adecuado para el ejercicio de su autonomía como función de expresión profesional. La fortaleza del docente es la que configura, a su vez, la fortaleza de la institución. Es entonces, en la articulación de estos dos polos -lugares físicos concretos y a la vez simbólicos- donde los docentes logran configurar la potencia emblemática de la institución.

7. Las culturas emergentes La Cultura, en su sentido lato, surge como un entramado complejo de significados que es dotado de sentido a través de las diferentes interpretaciones derivadas de las visiones -tanto personales como institucionales- que se analizan en este trabajo. Como constructo social, la cultura impregna e invade lo institucional desde sus orígenes históricos, hasta incluso las propias historias personales de su capital humano. Como cultura institucional y como culturas de trabajo se constituyen en factores de subordinación o exclusión de los actores involucrados.

8. Lo formativo como esencia; lo ético como sustento En la formación de los docentes, las fuentes teóricas son esenciales, pero por sí solas no son suficientes para alcanzar las metas educativas propuestas; se requiere de un plus por parte del docente, que implica su involucramiento total en la tarea. Esta actitud esperada del docente implica una construcción ética y moral del oficio de educador, que implica la responsabilidad, el reencuentro con los textos, el buen clima de aula, la educación como fuente de logros. Aquí se encuentra la respuesta del buen docente, que genera buena enseñanza. 


\section{Reflexiones finales}

Desde diferentes fuentes de información se procuró dar respuesta a las preguntas planteadas con el propósito de generar categorías interpretativas de la concepción de enseñanza del universitario sin formación pedagógica. Del análisis de las fuentes utilizadas se pueden deducir cruces transversales a partir de los cuales se interpretan los diferentes escenarios por los que discurren las historias personales y las historias institucionales que han constituido referente obligado, donde el poder y la cultura se constituyen en encuadre del contexto.

La cultura emerge en las palabras y en los documentos como producto arbitrario, construido e impuesto. Se percibe como algo natural, evidente y objetivo, pero sin embargo no emana directamente de la naturaleza. Son los individuos y sus actos los que construyen este entramado complejo, diverso e incierto que genera finalmente su identidad.

Cada estructuración cultural, en su construcción y reconstrucción, determinará las diferentes formas de expresión del poder: existe una cultura general imperante a nivel social y también una cultura institucional. Cada una de ellas, en forma consensuada o conflictiva, da lugar a diferentes expresiones de poderes emergentes. Tanto a nivel social macro, como a nivel micro, institucional, existen diversas formas de cultura que se entrelazan con las diversas formas de poder imperantes en cada momento o en cada contexto social e histórico. Y estos contextos adquirirán protagonismo siendo determinantes en los análisis realizados.

Esto se percibe claramente en los enfoques teóricos que dan lugar a los diferentes modelos docentes y en la contextualización de los documentos analizados. Una cosa es el IPA en el análisis que se realiza desde los Anales y que corresponde a una época y a una concepción de enseñanza y otra distinta es la visión de los docentes entrevistados en los cuales aparece la marca de los contextos en sus historias personales, en las referencias a su formación. Una cosa es la mirada de la Universidad en las etapas históricas en que la formación de sus docentes no es todavía motivo de preocupación, y otra diferente es actualmente, cuando esa formación logra un espacio en el currículo universitario.

\section{A propósito del I nstituto de Profesores Artigas}

En sus orígenes, el IPA se creó con el cometido de llevar a cabo la formación de profesores para la Enseñanza Media. Esto se realiza tomando como referente a la organización universitaria aunque dotando a la nueva institución con un perfil propio determinado por las actividades pedagógicas que va a desempeñar. Se piensa, en un Instituto Pedagógico o Facultad de Pedagogía que se estructure en torno a las Ciencias de la Educación.

De los documentos analizados y que hacen referencia a sus cometidos, vemos que éstos van más allá de la mera formación de los futuros docentes. Sin desprenderse del modelo social vigente se percibe a la educación, e implícitamente a la enseñanza, como instrumento socializador, y al docente en el desempeño de su oficio como el hacedor responsable de fomentar en sus alumnos no sólo la formación en su especialidad, que es condición indispensable, sino también el desarrollo de un espíritu emprendedor y de superación. Esto implica la existencia de una real preocupación referida a cómo aprenden los que enseñan, es decir por la formación de aquellos que serán los formadores de los futuros docentes. 
Aparecen como mandatos fundacionales referencias específicas con un "claro sentido cultural", en cuanto a la necesidad de formación y actualización de sus docentes. En esa formación no sólo se apuntaba a logros académicos, sino que también se ponía el acento en la responsabilidad, compromiso y ética que conlleva esta profesión, que se sustenta en tres pilares fundamentales: lo disciplinar, la formación pedagógica y la práctica. Todo esto requiere un elevado grado de compromiso que debe manifestarse en expresiones de autoridad moral e intelectual.

El docente del IPA adquiere un estatus especial, es considerado funcionario del Estado cuando desempeña tareas en la educación pública, siendo regido por las normas jurídicas contenidas en el Estatuto del Funcionario Docente. El docente será docente y algo más, lo que demuestra que el concepto de enseñanza, incluso en el imaginario social, va más allá de la sola reproducción del conocimiento.

\section{A propósito de la Universidad de la República}

De los análisis documentales de la Universidad de la República hemos podido constatar que su proceso de creación y su historia posterior acompañan los avatares de la identidad de nuestra nación, una vez surgida a la vida independiente.

Iniciada la andadura propia de nuestro país surge, en los primeros albores de la construcción nacional, el deseo de dotar a la República de una enseñanza organizada que cubriera los estudios primarios, medios y superiores, proceso que se inicia en 1849 con la instalación efectiva de la Universidad.

Su primer Reglamento orgánico le otorgó la totalidad de la enseñanza en sus tres niveles, complementada casi inmediatamente con la configuración de la educación como monopolio oficial del Estado. Las luchas posteriores de la Universidad se centran en el logro de la autonomía universitaria y el co-gobierno de los tres órdenes tradicionales que logra finalmente ser reconocido con rango constitucional en la Constitución de 1917 y que la Ley Orgánica de 1958, actualmente vigente, vino a consolidar.

Los sucesos históricos que tuvieron lugar a partir de los 70 abrieron un gran paréntesis en el desarrollo de la Universidad, que recién pudo normalizar su andadura institucional a partir de la restauración democrática de 1985.En esa fecha se vuelven los ojos a un proyecto trunco de la época del Rectorado Maggiolo donde se abordaba la ubicación de la Universidad con relación al vasto campo de la educación.

Esto sólo se podría lograr si la Universidad encaraba también la preparación de educadores para los Institutos de Enseñanza Media y para los Institutos Normales. Es evidente que esto significaba adoptar una actitud fuertemente crítica a la tarea realizada por estos centros educativos, que se confirma con la propuesta de que en el seno de la Universidad debía crearse un Instituto o Facultad de Ciencias de la Educación.

Los sucesos políticos acontecidos no permitieron que este plan se llevara a la práctica, pero sus postulados fueron retomados progresivamente desde los inicios de la década de los 90. La transformación de la Facultad de Humanidades y Ciencias, dando ingreso a las Ciencias de la Educación, recogía parte de las ideas formuladas por Maggiolo; esta reforma implicó la aparición de una Opción Docencia con un alcance discreto. 
El Plan Estratégico de la Universidad de la República, de 2001, avanzó en el abordaje de los temas educativos, estructuró una serie de orientaciones y proyectos tendientes a dotar a los docentes universitarios de una formación pedagógica didáctica.

Una vez realizado el análisis documental del IPA y de la Universidad podemos observar que ambas Instituciones surgen con finalidades diferentes, en cuanto al tema específico de la enseñanza.

Mientras que en el IPA la enseñanza es su objetivo explícito, en la Universidad ese objetivo está constituido por la formación de profesionales en cada especialidad.

Sin embargo implícitamente, también la Universidad tiene su concepción de enseñanza; como institución tiene una filosofía que impregna a sus egresados y que se reproduce por su mediación, en el ejercicio profesional. Por eso la tarea docente es percibida como una extensión de esa profesionalidad.

\section{A propósito de las narraciones}

Los datos surgidos de la revisión documental realizada se articulan con las voces que emergen de las entrevistas analizadas, en las que los docentes conforman sus narraciones permitiéndonos, a partir de sus propias palabras, reconstruir sus historias personales, de las cuales van surgiendo, poco a poco, sus concepciones de enseñanza.

Como lo expresáramos en los enunciados categoriales, los universitarios que se acercan a la docencia lo hacen desde diferentes vertientes y por motivos también distintos que cubren un amplio registro que va desde las vivencias contenidas en los juegos infantiles o en la imitación de modelos familiares (en los que se percibe un fuerte peso de las cuestiones de género en una carrera que, como la docente, en los últimos siglos ha contado con una presencia cada vez mayor de mujeres), hasta la huella profunda marcada por los docentes memorables, pasando por aquellos determinados por la necesidad de tipo laboral, o incluso de verdaderas vocaciones tempranamente detectadas y asumidas, que muchas veces se vieron frustradas 0 dificultadas por elementos contextuales, entre los cuales cabe destacar -por su impacto insoslayable-, el de la dictadura militar. No dejando de lado incluso la casualidad como motivo de acercamiento a la docencia, al acceder a ella en muchos casos los docentes descubren un verdadero gusto por enseñar; descubrimiento que, para otros, ha constituido una fuerte motivación en la continuidad de su desempeño profesional.

Lo que todos ellos señalan con un importante grado de coincidencia es la satisfacción lograda por el contacto humano, por el vínculo establecido, por el compartir. Podemos apreciar que el universitario en su desempeño docente no muestra una especial preocupación por no tener formación formal.

Todos los entrevistados poseen experiencia previa en docencia ya sea en ámbitos formales (Primaria, Secundaria, Universidad) o informales (clases particulares, instituciones privadas o ámbitos de capacitación) antes de llegar a las instancias de formación docente. Todos manifiestan no tener conocimientos didáctico -pedagógicos elaborados en ámbitos formales de enseñanza previos a su llegada al IPA, pero sin embargo es posible detectar orientaciones en este sentido. Implícitamente tienen una formación que no es percibida como tal ya que ha sido recibida en ámbitos o situaciones no convencionales como puede ser la guía de una madre maestra en torno a la mesa de la cocina, o de un marido docente universitario, o de una ex- Directora del colegio de la infancia. 
Lo didáctico, lo pedagógico, no son temas problemáticos para ellos ya que no suelen plantearse cuestionamientos en este sentido en el momento de tener que enfrentar una instancia de aula. Para estos docentes, en su gran mayoría, este déficit se cubre con la intuición, la reflexión, el análisis o el sentido común, así como por los modelos docentes que los inspiraron u orientaron.

En ellos ocupa un lugar fundamental la reproducción de los modelos escolares aprendidos como referente de cómo concretar esa enseñanza.

El aula se transforma en un espacio de autonomía, donde se enfrenta el desafío de enseñar, el saber la disciplina, los marcos epistemológicos, los contextos históricos, la actualización bibliográfica y el nivel de exigencia. Todos estos elementos deben conjugarse en un ámbito respetuoso y con un buen clima, ambos responsabilidad del docente que, de esta forma asegura a la Institución el correcto cumplimiento de su rol.

Esto es un proceso lento, con un fuerte referente en la propia práctica, que es vivido de diferentes maneras por cada uno: en algunos casos se desarrolla en soledad y en otros se forja en un compartir con los colegas, que también se transforman en un componente de la validación de su tarea en los ámbitos de la interacción simbólica cultural.

La formación docente para muchos de los entrevistados no es percibida como necesaria, o incluso es rechazada, pero sí se considera importante la implementación de cursos de profundización en las especialidades o en las Ciencias de la Educación.

Estas demandas, que coinciden con las propuestas institucionales relevadas en los Anales y que en ese contexto implica que el IPA debería asumir responsablemente la necesidad de proveer cursos de formación y profundización de sus docentes, en vías de mejorar su práctica, cuando son planteadas por los propios docentes derivan en realidad de una crítica a la institución por esa carencia. Pero al realizar esta crítica, ninguno de los entrevistados es consciente de que se refiere al incumplimiento de los mandatos fundacionales.

Enfrentados al contexto de enseñanza, aparece en todos los entrevistados una marcada preocupación por los temas relativos a la Educación a los efectos de lograr mejoras sustantivas en su práctica docente.

Una vez que ingresan al IPA se dan cuenta que no les alcanza sólo con el conocimiento de la asignatura y por eso han realizado o están realizando cursos complementarios en referencia a la Educación, ya sea de grado, como por ejemplo la Licenciatura en Ciencias de la Educación, o de postgrados.

Lo que siempre han tenido claro es la necesidad del conocimiento disciplinar como condición esencial para poder enseñar. Esto es, a su entender, parte de su profesionalidad. Aman lo que hacen, por su propio sentido profesional porque lo que tienen asumido claramente es el compromiso ético de todo universitario de devolver a la comunidad parte del bagaje intelectual y profesional que han recibido. Y esto lo pueden hacer desde un contexto de ejercicio de su especialidad académica, o a través de la investigación, o incluso a través de las tareas docentes.

Es decir, que esta última es percibida como una más de las tantas posibilidades que tienen a su alcance por su propia condición de universitarios. Ser universitarios y trabajar en el IPA fortalece la convicción de que se es bueno en el desempeño de la tarea de enseñar, ya sea que ésta se realice en los ámbitos universitarios o en los de formación docente. La Universidad da el conocimiento de la asignatura y el IPA la responsabilidad del enseñar. 
Asumen que su trabajo lo deben realizar con adultos; es allí donde sienten que deben desempeñar su oficio: en niveles terciarios o universitarios donde lo fundamental es el conocimiento disciplinar. En esos niveles pues, la enseñanza se percibe como una tarea de mayor jerarquía y para la cual están preparados.

Por eso también asumen la evaluación como inherente a su desempeño más que como un problema didáctico. En este ámbito es donde recurrentemente reivindican su parcela de poder como profesores. La facultad de evaluar es lo que los legitima como tales.

Tienen en su gran mayoría encarnado el sentido de la autoridad moral que deriva de su profesionalidad, y es en este campo que se sienten legitimados y donde asumen su responsabilidad como enseñantes: cualquiera podrá poner en tela de juicio sus métodos, pero no los contenidos que transmiten, porque de eso ellos son los que saben.

Llegan a aceptar entonces que el que sabe cómo enseñar es el egresado del IPA, pero también que eso no invalida su tarea en este nivel donde lo que consideran más importante es el conocimiento de la asignatura.

\section{A propósito de la visión institucional}

A la voz de los docentes entrevistados, debemos sumar ahora la especial visión que como informantes calificados tiene el equipo de Dirección del IPA.

Nos brindan una perspectiva holística desde sus sentimientos de pertenencia, sus experiencias, y la responsabilidad del cargo que ocupan, enmarcados fuertemente por los códigos culturales simbólicos que se construyen en el interior del IPA y que, como manifiestan, no les son ajenos.

Desde sus discursos surgen elementos recurrentes que los vinculan directamente con las diferentes fuentes ya analizadas. Su formación docente, el desempeño profesional y el ingreso a la Dirección se producen por motivos semejantes a los del resto de los entrevistados.

Van recorriendo caminos que se originan en razones económicas o vocacionales (este último caso asumido casi como un proceso que se fue dando en forma "natural").

También aparece la influencia de los entornos familiares, de los docentes que marcaron huella y orientaron, así como del contexto de la dictadura irrumpiendo en las narraciones.

Sus historias personales y su formación docente en el IPA, conforman otra mirada a lo institucional, pero desde una perspectiva diferente. Esta se construye desde la simbiosis de las trayectorias curriculares y de la posición jerárquica detentada.

Se hace especial referencia, por ejemplo, a docentes fundadores de esta institución que se recuerdan como representantes de un momento social e histórico y que son definidos como memorables, adalides de la ética profesional, comprometidos con llegar a formar, más que buenos enseñantes, buenos educadores.

Desde aquí y en más, las referencias a los principios fundacionales de la Institución acompañarán las narrativas implícita o explícitamente. Sus historias personales y la de la institución se irán construyendo en un proceso complejo que amalgama acciones docentes y jerárquicas. 
Desde la Dirección se ratifican ideas que se construyeron en otros momentos anteriores, de carácter formativo, para las que el aula y la práctica constituían el campo fundamental del desempeño, de la formación y de la responsabilidad del docente.

Campo también fortalecido por la influencia de sus pares, que además confirmaban que el ejercicio docente podía ser de todo, menos fácil.

En forma explícita, reivindican, como un componente significativo en el ejercicio de la práctica, el espacio de la didáctica, que se construye desde lo teórico en un lugar específico, el IPA, con sus cincuenta años de existencia y un contenido fundacional que prevalece en todos sus egresados. Esta rígida estructura compleja y diversa, adquiere dinamismo, según el decir de ambos Directores, en el ejercicio de la autonomía que tienen los profesores en el desempeño de su oficio docente.

Expresan, coincidentemente, que es a través del cuerpo de educadores que se renueva el IPA; por eso se torna tan importante el intercambio entre ellos y los ámbitos específicos de encuentro que los articulan, como son, por ejemplo, sus Salas Docentes.

También refieren que el IPA genera una cultura institucional propia que se determina en el currículo explícito y el oculto y que se expresa en una especial cultura de trabajo. Y agregan al respecto que este particular constructo se constituye en punto de referencia para el desempeño laboral de todos los docentes, encauzando la concepción de enseñanza, en sus múltiples vertientes.

Esta peculiaridad del IPA es reivindicada explícitamente por uno de los informantes, como parte del currículo oculto de la institución. Se tiene la convicción de que existe una forma diferente de enseñanza, distinta de la universitaria, y marcada por una preocupación personalizada por el alumno, en la cual se valora la manera de enseñar, que va más allá de la forma meramente lineal de transmisión del conocimiento.

Esto se percibe como una fortaleza institucional que da características propias al egresado de Formación Docente. El cómo aprendió, lo caracteriza y diferencia; reproducir esa cultura institucional implica asumir un plus que lo proyecta más allá del solo conocimiento de la asignatura transformándolo finalmente en un buen docente.

De este proceso el docente es el artífice fundamental; sobre él pesa el cometido de enseñar en el amplio sentido del término, a tal punto que se asume que si algunos alumnos pueden llegar a rechazar una asignatura, es debido al mal desempeño del rol docente.

El educador es un modelo y debe internalizarlo en el alumno, logrando establecer con él un fuerte vínculo que se convierte, para este último, y en palabras de este informante, en una especie de adicción.

Este vínculo es también percibido como uno de los puntos fuertes esenciales de la Institución: se logra principalmente a través de la responsabilidad del docente, por lo que lo administrativo, lo estructural y lo infraestructural, devienen factores complementarios. 
Todos estos elementos, en conjunto, permiten construir lo que nuestro informante denomina "la Cultura de Centro". Esta cultura, que finalmente impregna a todos los actores involucrados en la Institución, se logra construir aun cuando el cuerpo docente de la misma provenga de diferentes vertientes formativas, encontrándonos con egresados de Formación Docente, o de la Universidad, o incluso con docentes que poseen doble titulación desde el grado, o postgrados.

Este aspecto de su formación, se constituye en parte importante de la evaluación realizada desde la Dirección y además se complementa con los derivados de lo formal administrativo, como pueden ser, por ejemplo, la puntualidad, la asiduidad, o el grado de colaboración.

Al tener que evaluar su desempeño en la institución, los informantes calificados indican que junto a estos últimos elementos señalados, el concepto de enseñanza que cada uno de los docentes sostiene y transmite se convierte en un tópico a tener en cuenta.

Los elementos formativos no necesariamente se traducen en una buena enseñanza. Aunque sí es posible formular un cierto criterio al respecto; se cree, por parte del equipo de Dirección, que en el caso de los docentes de origen universitario los que estarían en mejores condiciones serían: por un lado aquellos que, con su titulación profesional, desempeñan además tareas en la Enseñanza Secundaria, que es el destino de los alumnos que están formando; y por otro aquellos que se especializan y actualizan en temas de educación preocupados por la mejora de su propia práctica.

Con relación a este tema de la actualización vemos que aparece una coincidencia entre los reclamos provenientes del campo docente y la convicción manifestada por el equipo de Dirección en cuanto a la necesidad y conveniencia de su implementación. Sin embargo percibimos una tensión subyacente y no totalmente resuelta en este tema, ya que mientras el cuerpo docente reclama algo que es un mandato fundacional y de responsabilidad de la propia Institución, desde ésta, si bien hay acuerdo con este concepto, no se logra instrumentar una respuesta adecuada.

En la adopción del criterio que se señalaba anteriormente, se tienen también en cuenta las particularidades personales de cada docente, que vienen dadas por las vertientes éticas, morales, que son entonces valoradas como elementos fundamentales en la elaboración del modelo docente que debe integrarse a la cultura institucional vigente. Si esta integración no se lograra, culminaría con el alejamiento del docente debido a la imposibilidad de trabajar armónicamente en la institución.

En estos procesos evaluativos constatamos que, al igual que sucedía en el caso de los docentes entrevistados, se configura un ámbito de poder que deriva del propio ejercicio de la función directiva, pero a su vez, reivindican implícitamente el poder del docente en su aula en el ejercicio de su autonomía. Queda claro que el campo de la enseñanza es privativo y responsabilidad del docente: no hay que olvidar que en este nivel terciario el alumno es un adulto y por tanto es quien debe responsabilizarse de su aprendizaje.

A pesar de esta autonomía relativa reconocida al docente, la función de formar conlleva la responsabilidad de fomentar la motivación de los alumnos, propiciar su reencuentro con los libros, hacerles comprender la importancia de la educación, así como lograr establecer con ellos el vínculo necesario para alcanzar estas metas, ya que todo esto forma parte de lo que se definiría como una buena enseñanza. 
Sin negar entonces la importancia de la formación docente, a la que ven como indispensable en los niveles educativos de primaria y secundaria, uno de los informantes considera que cuando se trata de conformar una buena enseñanza en el nivel terciario o universitario, la clave está en su personalización, en la profundización del conocimiento desde la especialidad, así como en el cumplimiento de los elementos formales ya mencionados. La cuestión deviene, por lo tanto, un tema de ética en el ejercicio de la docencia.

En esa búsqueda del concepto de lo que consideran buenos docentes, es decir, aquellos que son capaces de generar una buena enseñanza, uno de los informantes le confiere especial relevancia al aporte de la didáctica. Destaca que ésta es un saber pensar sobre y desde la práctica, y un saber hacer en sentido epistemológico. Elementos éstos que se conjugan en una construcción social dinámica y compleja dirigida a metas moralmente valiosas que, para nuestro caso, son las relacionadas con la formación de aquellos que serán a su vez formadores de los adolescentes de nuestra sociedad.

Por tanto, el aspecto epistemológico así como la construcción moral de la profesión - ya sea que se las analice desde lo sistémico, es decir respondiendo al buen cumplimiento de las funciones; o desde las vertientes críticas, analizando cuidadosa y reflexivamente las realidades a los que uno se ve enfrentado en el devenir cotidiano - constituyen los fundamentos de una buena enseñanza.

La actividad del buen docente, o la buena enseñanza, no comienza y acaba en el aula sino que por el contrario, en una mirada no alienante, debemos asumirla como una profesión que es parte constitutiva de nosotros en todo momento.

\section{Conclusiones}

Analizados finalmente los datos relevados de las diferentes fuentes de información y realizada la triangulación correspondiente entre los mismos, estamos en condiciones de concluir que las concepciones de enseñanza de los docentes universitarios experimentados que trabajan en el IPA sin formación pedagógica, no se ajustan a un único modelo docente, ni a una única concepción de enseñanza.

Los modelos docentes puros no existen; todos los universitarios que se desempeñan como docentes en el IPA han tenido o tienen formación en Educación, ya sea en ámbitos formales o informales.

Las concepciones de enseñanza no se determinan solamente por lo formativo, es decir, por lo que deriva de su formación profesional; a ella coadyuvan multiplicidad de factores diferentes pero, sin embargo, se puede establecer que, en líneas generales, aparecen coincidencias entre las diferentes concepciones.

Desde los mandatos fundacionales del IPA la concepción de enseñanza aparece centrada en la generación del sentido de responsabilidad, compromiso y ética que conlleva la profesión docente, sustentada en los tres principios fundamentales de lo disciplinar, la formación pedagógica y la práctica.

Desde la Universidad la formación docente universitaria se concibe como un modelo de desarrollo profesional que apunta a la mejora de la calidad docente e investigadora, jerarquizando la reflexión sobre la práctica, entendiendo ésta como objeto de conocimiento en sus más amplias dimensiones: social, política, institucional y de aula. 
El docente universitario que se apasiona por su disciplina identificándose con eso que es su profesionalidad, que se preocupa por la educación y se impregna de la cultura institucional, constituiría el tipo ideal del modelo docente.

Cabe señalar por último que, como en todo trabajo de investigación a la vez que se obtienen respuestas para las cuestiones que determinaron su realización, también se originan una multiplicidad de nuevas inquietudes que permitirían el abordaje de otros análisis futuros. Cabría la posibilidad de generar estudios comparativos referidos a las concepciones de enseñanza de los docentes egresados de la Institución a los efectos de calibrar en su total significación los resultados obtenidos en este trabajo.

\section{Bibliografía y notas}

Atkinson, T. et.al. 2002. El profesor intuitivo. Barcelona: Octaedro.

Ball, S.1993. Foucault y la Educación. Disciplinas y saber. Madrid: Morata.

Barrios Pintos, A. 1971. Montevideo. Los barrios I. Montevideo: Nuestra Tierra

Barrios Pintos, A. 1990. Los barrios de Montevideo. Montevideo: Intendencia Municipal de Montevideo.

Berstein, B. 1993. La estructura del discurso pedagógico. Madrid: Morata.

Bruner, J. 2003. La fábrica de historias. Buenos Aires: Fundación de Cultura Económica.

Camilloni, A. et al. 1996. Corrientes didácticas contemporáneas. México: Paidós.

Candau, U. 1989. Rumo uma Nova Didatica. Brasil: Vozes, RJ.

Carretero, M. (comp.) 1991. Procesos de enseñanza y aprendizaje. Buenos Aires: Aique.

Cook, T. y Reichardt, Ch. 1986. Métodos cualitativos y cuantitativos en investigación. Madrid: Morata

El proceso fundacional de la Universidad. [on line]. [citado 28/03/2004]. Disponible en Internet: http://www.rau.edu.uy/universidad/uni_hist.htm.

Ferry, G. 1991. El trayecto de la formación. Madrid: Paidós.

Foucault, M. 1991. Vigilar y castigar, nacimiento de la prisión. México: S. XXI.

Foucault, M. 1992. Microfísica del Poder. Madrid: La Piqueta.

Grompone, A. 1956. El Instituto de ProfesoresArtigas. En: Anales del Instituto de Profesores "Artigas" 1(1). Montevideo: ANEP.

Hargreaves, A. 1996. Profesorado, cultura y posmodernidad. Madrid: Morata.

Jackson, V. 2003. La vida moral en la escuela. Bs.As.: Amorrortu.

Litwin, E. 1997. Las configuraciones didácticas. Bs. As.: Paidós.

Parra, C. et al. (comps.), 2001. Didáctica de las matemáticas. Argentina: Paidós.

Plan Estratégico de la Universidad de la República. En: Documentos de Trabajo del Rectorado No 10. 2001. Montevideo: UDELAR. 
${ }^{1}$ Ropo, E. Diferencias en la enseñanza de docentes de inglés: expertos y principiantes. En Carretero, 1991, cap. 4.

2 Souto, M. La clase escolar. Una mirada sobre la didáctica de lo grupal. En Camilloni, A., 1996. Corrientes didácticas contemporáneas, Cap. 5.

${ }^{3}$ Brousseau, G., Los roles del maestro. En Parra, C. y Saiz, I. (comps.), 2001. Didáctica de las matemáticas. Cap. IV.

* Master en Educación, Universidad ORT. Diploma en Educación, Universidad ORT. Certificado de Actualización en Ciencias de la Educación, Universidad ORT. Licenciada en Sociología. Docente, Institutos de Formación Docente, en Sociología y Sociología de la Educación. Docente en Investigación Educativa. 